\title{
Residual stress effects on fatigue crack propagation in Butt-Welded joints for 304 stainless steel sheets
}

\author{
Eman El Shrief ${ }^{1}$, Abla El-Megharbel ${ }^{1, *}$, Aly El Domiaty ${ }^{2}$, and Hassan Abd El-Hafez ${ }^{1,3}$ \\ ${ }^{1}$ Production Engineering and Mechanical Design Department, Faculty of Engineering, Port Said University, Port Said, Egypt \\ 2 Mechanical Engineering Department, Faculty of Engineering, Suez Canal University, Ismailia, Egypt \\ ${ }^{3}$ Department of Mechanical Engineering, College of Engineering, Qassim University, Unaizah, Saudi Arabia
}

Received: 26 March 2021 / Accepted: 15 June 2021

\begin{abstract}
Welded joints are sensitive to fatigue failure due to cyclic loading, as well as fatigue crack propagation influenced by the distribution of welding residual stress. In this study, the fatigue crack propagation rates in butt-welded joints for 304 stainless steel sheets were evaluated in the presence of welding residual stresses. The analysis consisted of two separate models: first, a 3D-finite element (FE) model was used to predict the residual stresses due to welding; second, a numerical study was undertaken to predict fatigue crack propagation in the presence and absence of residual stress using the extended finite element method (XFEM). The crack growth model (NASGRO) and available experimental data were applied to verify the simulation results. The XFEM without residual stress effects shows good agreement with the experimental data and the NASGRO model. However, in the presence of residual stress, the simulation results show less agreement with the NASGRO model. The level and the nature of residual stress have significant effects on crack growth. A faster crack propagation rate is recognized due to the effect of tensile residual stress at the crack tip, while a higher resistance to crack growth is developed due to a compressive residual stress field.
\end{abstract}

Keywords: Fatigue crack growth / welding residual stress / extended finite element method / stress intensity factor / stainless steel

\section{Introduction}

Assessment of welded joints is based on numerous factors such as weld geometry; loading type and, residual stress which can produce an extensive impact on the fatigue performance of welded components [1]. Residual stresses can arise due to non-uniform plastic strain distribution in the welded zone caused by the difference between heating and cooling rates during the welding process. While residual stresses may be relieved in small-scale structures, they play a significant role in the fatigue performance of welded joints and should be considered in the joint design [2]. Tensile and compressive residual stresses often occur together in welded structures. For a free external load, the tensile residual stress is self-balanced by compressive residual stress. Tensile or compressive residual stresses may be executed on the crack tip due to the effect of crack length. Subsequently, the fatigue crack growth rate may increase due to tensile residual stress and decrease due to compressive residual stress [3].

\footnotetext{
* e-mail: aelmegharbel@eng.psu.edu.eg
}

Many researchers have studied residual stress redistribution by crack growth and its influence on fatigue crack growth when the crack orientation was perpendicular to the welding line. Lee et al. [4] used two techniques (hole drilling and magnetizing stress indication) and observed that the longitudinal residual stress decreased by increasing the notch length. Sutton et al. [5] determined longitudinal residual stress experimentally using the cutcompliance method, and concluded that by growing the crack into the weld region, the crack was arrested due to the high compressive residual stress. Liljedahl et al. [6] explored the progression of residual stresses with crack growth for compact tension (CT) and middle tension (MT) specimens using a neutron diffraction technique. They detected that at the crack tip, the residual stress increases as the crack grows.

Zhu and Jia [7] suggested a novel method to study the influence of residual stresses on fatigue crack growth according to the cavity diffusion theory. Residual stresses were restrained using the X-ray diffraction technique. It was concluded that the neglected redistribution of residual stresses would overestimate the crack growth rate and 


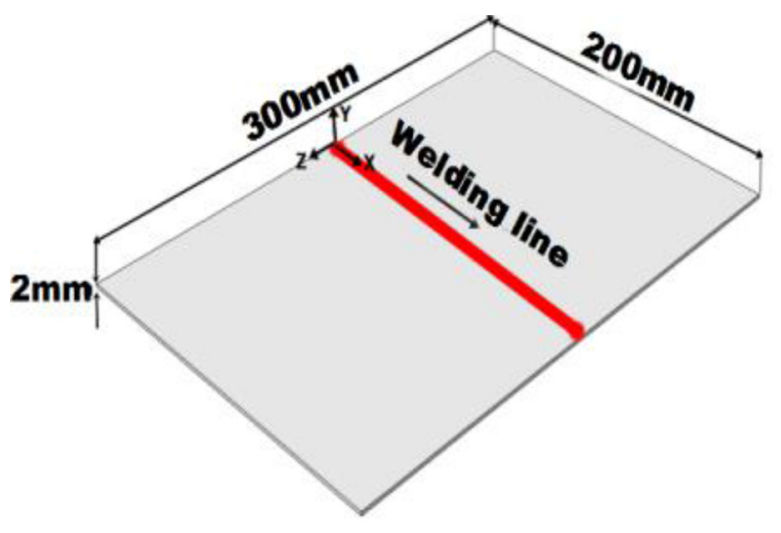

(a)

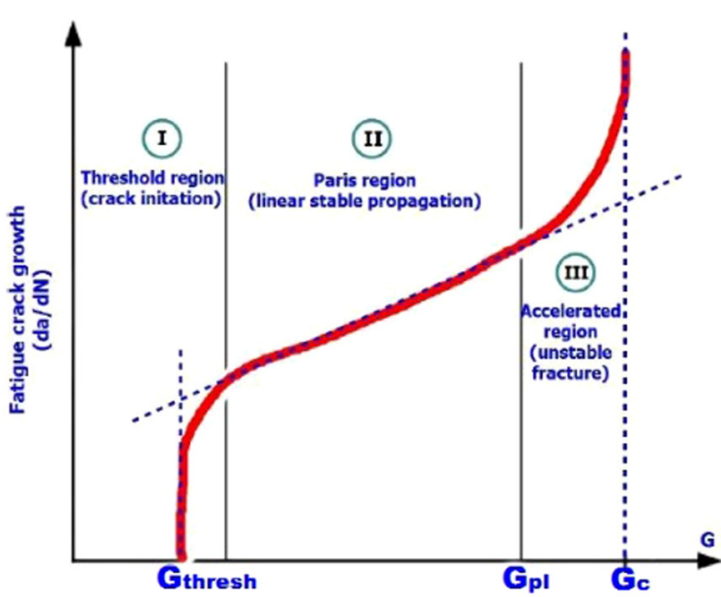

(b)

Fig. 1. (a) Dimensions of the geometrical model, (b) relationship between fatigue crack growth and energy release rate.

Table 1. Thermal and mechanical properties of 304 stainless steel [13].

\begin{tabular}{cccccccc}
\hline $\begin{array}{c}\text { Temperature } \\
(\mathbf{C} \mathbf{C})\end{array}$ & $\begin{array}{c}\text { Thermal } \\
\text { conductivity } \\
\left(\mathbf{W} / \mathbf{m} .^{\circ} \mathbf{C}\right)\end{array}$ & $\begin{array}{c}\text { Density } \\
\left(\mathbf{k g} / \mathbf{m}^{\mathbf{3}}\right)\end{array}$ & $\begin{array}{c}\text { Specific } \\
\text { heat } \\
\left(\mathbf{J} / \mathbf{k g}{ }^{\circ} \mathbf{C}\right)\end{array}$ & $\begin{array}{c}\text { Young's } \\
\text { modulus } \\
(\mathbf{G P a})\end{array}$ & $\begin{array}{c}\text { Yield } \\
\text { stress } \\
(\mathbf{M P a})\end{array}$ & $\begin{array}{c}\text { Poisson's } \\
\text { ratio }\end{array}$ & $\begin{array}{c}\text { Thermal } \\
\text { expansion } \\
\text { coefficient } \\
\left(\mathbf{l}{ }^{\circ} \mathbf{C}\right)\end{array}$ \\
\hline $\mathbf{0}$ & 14.6 & 7900 & 0.462 & 198.5 & 265 & 0.294 & $1.70 \mathrm{E}-05$ \\
$\mathbf{1 0 0}$ & 15.1 & 7880 & 0.496 & 193 & 218 & 0.295 & $1.74 \mathrm{E}-05$ \\
$\mathbf{2 0 0}$ & 16.1 & 7830 & 0.512 & 185 & 186 & 0.301 & $1.80 \mathrm{E}-05$ \\
$\mathbf{3 0 0}$ & 17.9 & 7790 & 0.525 & 176 & 170 & 0.31 & $1.86 \mathrm{E}-05$ \\
$\mathbf{4 0 0}$ & 18 & 7750 & 0.54 & 167 & 155 & 0.318 & $1.91 \mathrm{E}-05$ \\
$\mathbf{6 0 0}$ & 20.8 & 7660 & 0.577 & 159 & 149 & 0.326 & $1.96 \mathrm{E}-05$ \\
$\mathbf{8 0 0}$ & 23.9 & 7560 & 0.604 & 151 & 91 & 0.333 & $2.02 \mathrm{E}-05$ \\
$\mathbf{1 2 0 0}$ & 32.2 & 7370 & 0.676 & 60 & 25 & 0.339 & $2.07 \mathrm{E}-05$ \\
$\mathbf{1 3 0 0}$ & 33.7 & 7320 & 0.692 & 20 & 21 & 0.342 & $2.11 \mathrm{E}-05$ \\
\hline $\mathbf{1 5 0 0}$ & 120 & 7320 & 0.935 & 10 & 10 & 0.388 & $2.16 \mathrm{E}-05$ \\
\hline
\end{tabular}

therefore lead to a more conventional result. Ferro et al. [8] proposed a model to evaluate the effect of residual stresses on the fatigue life of butt-welded joints by considering the influence of fatigue loading on the redistribution of residual stress. They found that the fatigue loading amplitude affects the performance of the residual stresses.

The extended finite element method (XFEM) has been used extensively in recent studies to help alleviate the limitations of the finite element (FE) method. The XFEM was used to model the propagation of various discontinuities, such as crack growth analysis without the need for re-meshing, and also to calculate the stress intensity factor [9]. Elshrief et al. [10] studied the influence of welding residual stress and crack orientation on determining the stress intensity factor for butt steel joints using the XFEM. Ranjan Mishra et al. [11]used the XFEM for the fatiguecracking behavior of piezo-electric structures under cyclic thermal-electrical-mechanical loads. Abdullah et al. [12] presented the first approach to model crack propagation and assess the structural integrity of cracked composite plates under the aeroelastic condition coupled with XFEM.
There are few numerical studies on fatigue propagation prediction in a residual stress field using 3D-XFEM for stainless steel. Therefore, we aimed to simulate fatigue crack growth in 304 stainless steel before and after welding, under a cyclic fatigue load, taking into consideration residual stress distribution.

\section{Finite element modeling of welding residual stress}

A full-scale, 3D-FE model for two 304 stainless steel plates of $300 \times 200 \mathrm{~mm}$ with a $2 \mathrm{~mm}$ thickness was created to simulate welding, as illustrated in Figure 1a, using a sequential thermo-mechanical numerical analysis. The welding parameter preferred for this analysis are; welding speed of $2.5 \mathrm{~mm} / \mathrm{s}$, welding current of 200 amperes, welding voltage of 25 volts, and the convection heat transfer is $60 \times 10^{-6} \mathrm{~W} / \mathrm{mm}^{2} \mathrm{~K}$. The thermal and mechanical properties of 304 stainless steel dependent on temperatures are listed in Table 1. First, thermal analysis was carried out to 
estimate the temperature distribution by the heat transfer analysis. It was performed on the transient thermal field induced in the material by moving the heat source. Next, the temperature field was used as a load in the mechanical analysis to compute the mechanical distortion and residual stress due to thermal strains. Welding residual stresses were used in the fracture model to study their effect on fatigue crack propagation.

\section{Fatigue crack growth rate based on XFEM}

The extended finite element method (XFEM) is a numerical approach in ABAQUS software that is used to examine fatigue crack growth using a combination of the direct cyclic approach and linear elastic fracture mechanics (LEFM). Generally, the propagation of a crack is considered using Paris law as defined in equation (1). In the XFEM, equation (2) is used to analyze the fracture according to Griffith's energy criterion [14], as shown in Figure 1b.

$$
\begin{aligned}
& \frac{\mathrm{d} a}{\mathrm{~d} n}=c \Delta K^{m} \\
& \frac{\mathrm{d} a}{\mathrm{~d} n}=c_{3} \Delta G^{c_{4}}
\end{aligned}
$$

where $\frac{\mathrm{d} a}{\mathrm{~d} n}$ is the fatigue crack growth rate, $\Delta \mathrm{K}$ is the stress intensity factor, and the energy release rate material constants $c_{3}$ and $c_{4}$ depend on parameters $c$ and $m$ of the Paris formula and can be expressed as [14]:

$$
c_{3}=c E^{c_{4}} \quad c_{4}=m / 2
$$

The fatigue crack growth initiation is realized as [14]:

$$
f=\frac{N}{c_{1} \Delta G^{c_{2}}} \geq 1
$$

where $c_{1}$ and $c_{2}$ are constants that denote the beginning of the fatigue crack growth and are usually kept at small values such as 0.001 and zero, respectively; $N$ is the number of cycles, and $\Delta G$ is the difference between the values of the fracture energy release rate. As shown in Figure 1b, the interface elements at the crack tips will not be released and the cracks will not start to propagate unless the maximum fracture energy release rate $\left(G_{\max }\right)$ is greater than the threshold fracture energy release rate $\left(G_{\text {thresh }}\right)$ and less than the upper limit of the energy release rate $\left(G_{\mathrm{pl}}\right)$, i.e., $G_{\text {thresh }}<G_{\max }<G_{\mathrm{pl}}$.

To study the influence of welding residual stress on fatigue crack growth, the superposition method is applied, where the total stress intensity factors from both welding residual stress and externally applied load can be superposed together [15].

$$
K_{\text {eff }}=K_{\text {app }}+K_{\text {res }}
$$

The fatigue crack growth rate can then be rewritten as:

$$
\frac{\mathrm{d} a}{\mathrm{~d} n}=c \Delta K_{\mathrm{eff}}^{m}
$$

From the superposition method under cyclic loading, the total stress intensity factor range $\Delta K_{\text {eff }}$ and effective stress ratio $\left(R_{\text {eff }}\right)$ can be calculated as follows [15].

$$
\Delta K_{\text {eff }}=\left(K_{\text {app }, \max }+K_{\text {res }}\right)-\left(K_{\text {app }, \text { min }}+K_{\text {res }}\right)=\Delta K_{\text {app }}
$$

$$
R_{\mathrm{eff}}=\frac{K_{\mathrm{app}, \min }+K_{\mathrm{res}}}{K_{\mathrm{app}, \max }+K_{\mathrm{res}}}
$$

It is evident from equations (7) and (8) that the effective stress ratio will frequently change as the crack propagates due to residual stress, while the total stress intensity factor for the residual and applied external stresses $K_{\text {eff }}$ does not need to be considered.

\subsection{XFEM model geometry}

In this study, a 3D-XFEM model was established based on the same geometry displayed in Figure 1a. However, an initial center through-thickness fatigue crack (2a) perpendicular to the weld line crack was inserted to start the fatigue crack growth. The XFEM model was used to simulate the crack growth from the initial crack length until the failure. Based on the XFEM, the crack domain is defined as an enrichment region that includes the surface crack and crack tip, to attain the condition that cracks can grow in any direction.

\subsection{Material definition}

The definition of the basis of damage is an essential parameter for completing the analysis. Consequently, for damage initiation, the maximum principal stress failure criterion was chosen. However, a mixed-mode, energydependent damage evolution law was selected for damage propagation based on the power-law criterion. The mechanical properties of the investigated 304 stainless steel and fracture toughness parameters were based on the literature data [14]. However, the energy release rate constants $c_{3}$ and $c_{4}$ for different stress ratios $R=0.1$ and $R=0.25$ were checked with reference to [16,17], respectively, as these constants were not in [14]. The fatigue properties are listed in Table 2 .

\subsection{Mesh design and boundary condition}

The mesh design adopted in the sequential thermomechanical analysis is recognized in the fatigue crack growth simulation. The mesh size should be small enough to capture exact stresses in the welding zone and at the vicinity of the crack tip, however, a non-refined mesh is used elsewhere, as shown in Figure 2a. In this study, a linear diffusive heat transfer element (DC3D8) was used for the thermal analysis, while (C3D8I) linear elements with additional incompatible bending modes were used for mechanical analysis to estimate residual stress. In the XFEM model, linear hexahedron elements (C3D8R) were used to model crack propagation. The fine mesh element 
Table 2. Material constants for Paris' law and extended finite element method (XFEM).

\begin{tabular}{llllll}
\hline \multirow{2}{*}{ Loading stress ratio $(\mathrm{R})$} & \multicolumn{2}{c}{ Experimental constants } & & \multicolumn{3}{c}{ XFEM constants based on equation (3) } \\
\cline { 2 - 3 } & $\mathrm{C}$ & $\mathrm{m}$ & & $\mathrm{C}_{3}$ & $\mathrm{C}_{4}$ \\
\hline$R=0.1$ & $4.0 \mathrm{e}-12$ & 3.1152 & & $6.13299 \mathrm{e}-4$ & 1.5576 \\
$R=0.25$ & $6.0 \mathrm{e}-12$ & 3.0684 & $6.930 \mathrm{e}-4$ & 1.5342 \\
\hline
\end{tabular}
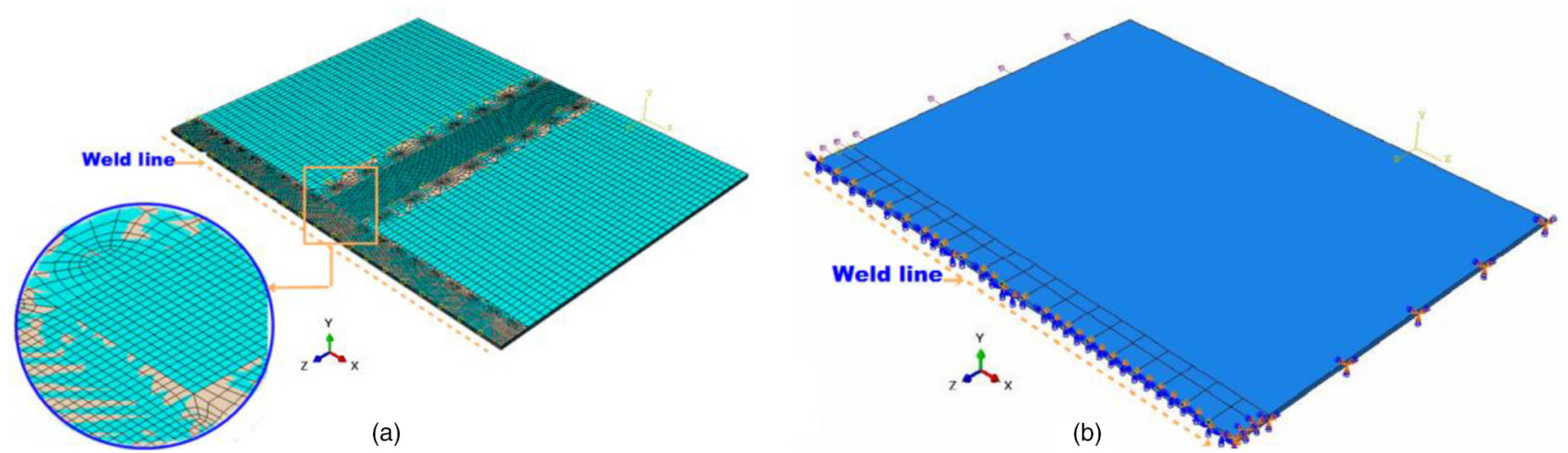

Fig. 2. (a) Mesh design for thermo-mechanical and fatigue crack growth analyses; (b) loading and boundary conditions for fatigue crack model.

size in the welding and crack zone was $1 \times 1 \times 0.5 \mathrm{~mm}$, while a $4.5 \times 2.5 \times 1 \mathrm{~mm}$ element size was used for the coarser mesh. Between the fine and coarser meshes, hexahedral elements with the bottom-up technique were used to establish transitions in element size.

\subsection{Loading and boundary condition}

In respect of the XFEM, loading and boundary conditions are presented in Figure 2b. For loading, a periodic load defined as an amplitude function depending on loading stress ratio $R$ along the $\mathrm{X}$ direction is applied. For boundary conditions, the loaded surface is controlled by fixed displacement in two directions $(\mathrm{U} 2=\mathrm{U} 3=0)$. The opposite surface is restricted for all degrees of freedom $(\mathrm{U} 1=\mathrm{U} 2=\mathrm{U} 3=0),(\mathrm{UR} 1=\mathrm{UR} 2=\mathrm{UR} 3=0)$. The fixed displacements for one direction $(\mathrm{U} 3=0)$ are applied to the symmetry surface plane. $\mathrm{U} 1=\mathrm{U} 2=\mathrm{U} 3$ demonstrate displacement along the $\mathrm{X}, \mathrm{Y}$, and $\mathrm{Z}$ axes, respectively. UR1, UR2, and UR3 demonstrate rotations around the $\mathrm{X}, \mathrm{Y}$, and $\mathrm{Z}$ axes, respectively.

\subsection{Fatigue crack growth verification}

Several relations were established for describing the fatigue crack growth rate. The crack growth model (NASGRO) is the most inclusive of the current crack growth models. In this study, the NASGRO model was used to verify the XFEM for fatigue crack growth rates at different load ratios. The NASGRO model characterizes the most complete crack growth law formulation, comprising stress ratio $(\mathrm{R})$ effects, the tails at the upper and lower ends of the growth rate curve, and crack closure, which considers the effect of plasticity [18]. The NASGRO equation is expressed as:

$$
\frac{\mathrm{d} a}{\mathrm{~d} n}=C_{N}\left[\left(\frac{1-f}{1-R_{\mathrm{eff}}}\right) \Delta K_{\mathrm{eff}}\right]^{m} \frac{\left[1-\frac{\Delta K_{\mathrm{th}}}{\Delta K_{\mathrm{eff}}}\right]^{p}}{\left[1-\frac{K_{\mathrm{max}}}{K_{\mathrm{Ic}}}\right]^{q}}
$$

The values $c_{N}, \mathrm{~m}, \mathrm{p}$, and $\mathrm{q}$ are empirical coefficients that were determined to fit the growth rate curve; $f$ characterizes the crack closure function [19] and is determined from the following formula:

$$
f=\max \left\{(R),\left(A \circ+A_{1} \cdot R_{\mathrm{eff}}+A_{2} \cdot R_{\mathrm{eff}}^{2}+A_{3} \cdot R_{\mathrm{eff}}^{3}\right\} \text { if } R \geq 0\right.
$$

The coefficients Ai are stated as follows:

$$
\begin{aligned}
& A_{0}=\left(0.825-0.34 \propto+0.05 \alpha^{2}\right)\left[\cos \left(\frac{\pi}{2} S R\right)\right]^{\frac{1}{\alpha}} \\
& A_{1}=(0.415-0.071 \propto) S R \\
& A_{2}=1-A_{0}-A_{1}-A_{3} \\
& A_{3}=2 A_{0}+A_{1}-1
\end{aligned}
$$

where $\propto$ is the plain stress constraint factor and SR is the ratio between the maximum applied stress and the flow stress. $\Delta K_{\mathrm{th}}$ is the threshold stress intensity range [19] and 
Table 3. Mechanical properties and parameters of the crack growth model (NASGRO) (MPa, MPa.m ${ }^{0.5}$ ) for 304 stainless steel.

\begin{tabular}{lllllllll}
\hline$C_{N}$ & $\mathrm{~m}$ & $\mathrm{P}$ & $\mathrm{q}$ & $\Delta K_{0}$ & $C_{t h}$ & $\mathrm{R}$ & $\propto$ & $S R$ \\
\hline $1.1486 \mathrm{e}-11$ & 3 & 0.25 & 0.25 & 3.8 & 0.1 & 0.7 & 2.5 & 0.3 \\
\hline
\end{tabular}

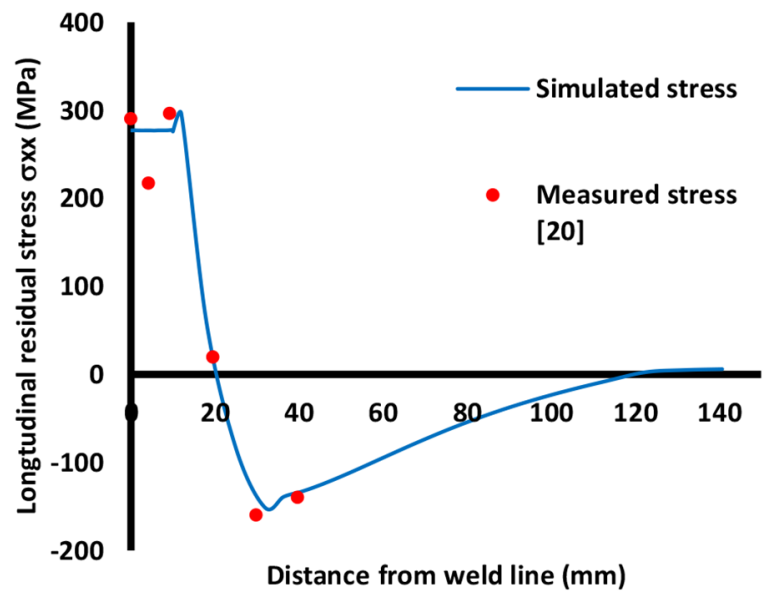

Fig. 3. Comparison of measured and simulated longitudinal residual stress responsible for Mode I of fatigue crack growth.

is obtained from the following equation:

$$
\Delta K_{\mathrm{th}}=\Delta K_{0}\left[\frac{1-f}{\left(1-A_{0}\right)\left(1-R_{\mathrm{eff}}\right)}\right]^{-\left(1+C_{\mathrm{th}} R\right)}
$$

where $\Delta K_{0}$ is the threshold stress intensity range and $C_{\mathrm{th}}$ is the threshold coefficient.

For constant amplitude loading, the parameter values of the NASGRO model are according to [17] and are listed in Table 3.

\section{Results and discussion}

\subsection{Residual stress distribution}

The residual stress distribution over the weld-joint was obtained using the simulation and validated using available previous experimental work [20] as shown in Figure 3. There is good agreement between the measured and numerical results. According to the numerical simulation, the residual stress demonstrates a maximum value of about $300 \mathrm{MPa}$ at the weld line, and then it decreases and creates compressive residual stresses away from the weld region to self-balance. The deviation between the predicted and measured residual stress may be a result of experimental errors due to measurement accuracy, the difference in plate dimensions, boundary conditions, or the input temperature-dependent material properties in the simulation.

\subsection{Fatigue crack propagation in absence of residual stress}

In Figure 4, the XFEM model for non-welded material has been verified using experimental and simulation data obtained by other researchers $[16,17]$ for $R=0.1$ and 0.25 , respectively. In addition, the data were compared with the results obtained from the NASGRO model. In the XFEM, the stress intensity factor values were calculated using the fracture energy criterion, where the crack propagated along the element length beginning from the initial crack size until failure. For the stress ratios $R=0.1$ and $R=0.25$, the slopes of the XFEM are 2.98 and 3.068, respectively. When comparing with the experimental results and the NASGRO model, it can be observed that the XFEM has a good correlation for $R=0.1$ with a maximum difference of $4.3 \%$ in the slope $(\mathrm{m})$ and $18 \%$ in the intercept $(\mathrm{C})$ of the Paris law. For $R=0.25$, the maximum difference is $2.6 \%$ in the slope $(\mathrm{m})$ and $14.28 \%$ in the intercept (C) of the Paris law.

The von Mises stress distribution fields and the crack propagation due to the effect of periodic load at $R=0.1$ are presented in Figure 5. Figure 5a displays the beginning of crack initiation; it is obvious that Mises stress concentrates at the tip of the crack. The crack propagates significantly along the symmetry plane of the model as shown in Figures $5 \mathrm{~b}$ and $5 \mathrm{c}$. The crack propagation is shown in Figure $5 \mathrm{~d}$, where the crack length is near the edge of the plate. It is noticed that the plate is completely fractured at $5 \times 10^{5}$ cycles.

\subsection{Fatigue crack propagation in the presence of residual stress}

Von Mises stress distribution is shown in Figure 6a, where there is no crack in the plate and the plate is under the effect of residual stress only. When the crack is inserted perpendicularly on the weld line, the crack initiation starts due to the combination of applying the cyclic load and residual stress, as shown in Figure $6 \mathrm{~b}$. The peak of the stress is seen in the vicinity of the crack tip; additionally, the plate fails due to accelerated crack propagation. Von Mises stress distribution is shown in Figures $6 \mathrm{c}$ and $6 \mathrm{~d}$ where the crack lengths propagate further. In the residual stress field, the central symmetry region is more damaged and the crack begins to deflect. By extending the model cycles, it is noticed that the plate is completely fractured at $9 \times 10^{4}$ cycles.

The relationship between the fatigue crack growth and the stress intensity factor at $R=0.1$ in the presence of residual stress is shown in Figure 7. There is a notable difference in crack growth rate behavior in the presence of 


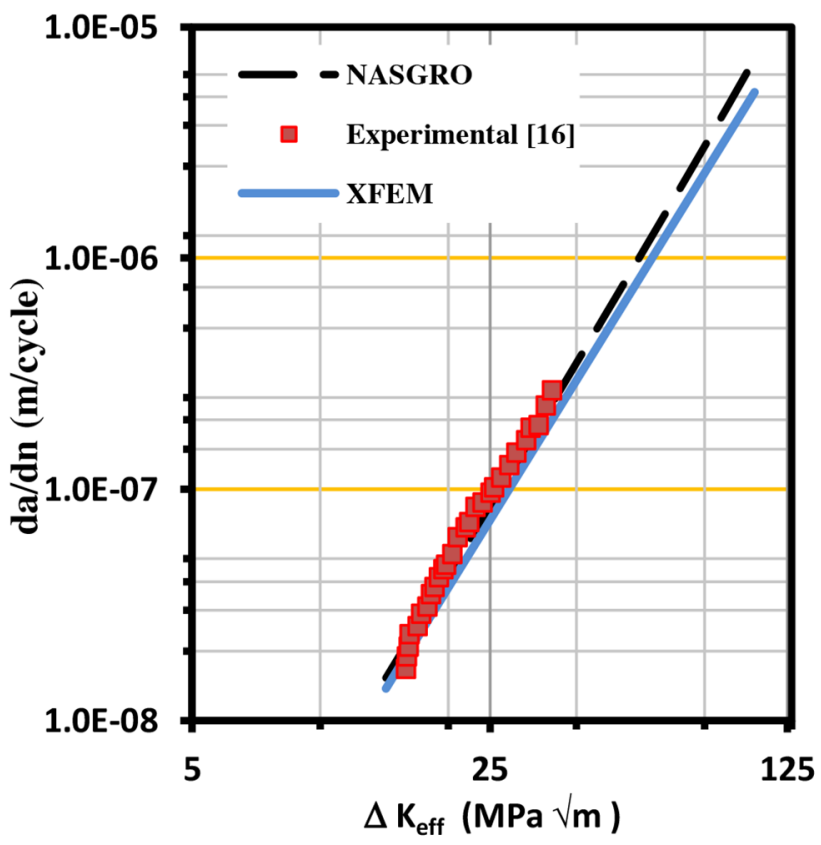

(a)

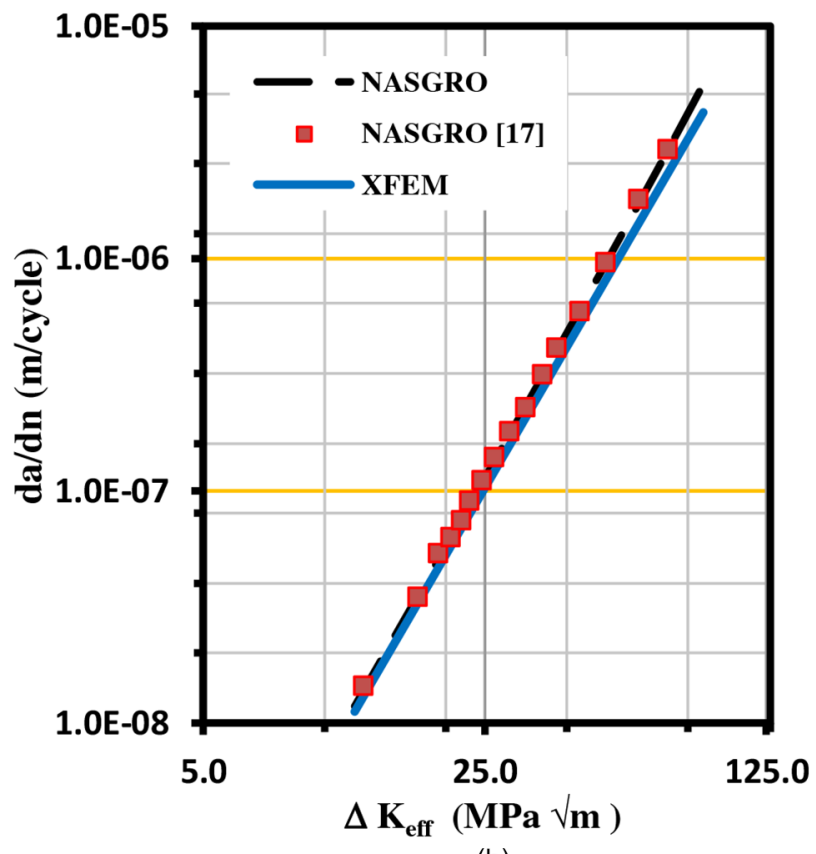

(b)

Fig. 4. Fatigue crack propagation rate $(\mathrm{da} / \mathrm{dn})$ without residual stress field at different stress ratios $(\mathrm{R}):(\mathrm{a}) R=0.1 ;(\mathrm{b}) R=0.25$.

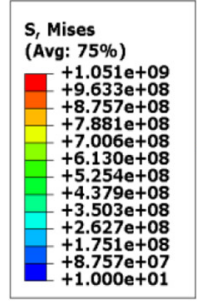

${ }_{2}^{y}$

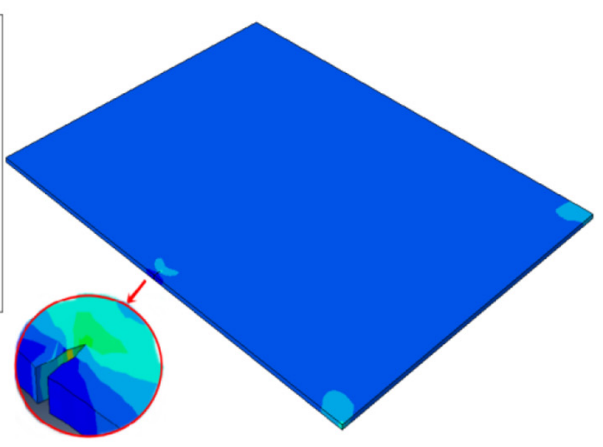

(a) $N=5.6 \times 10^{4}$ cycles

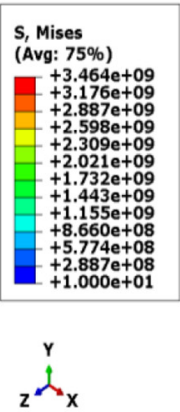

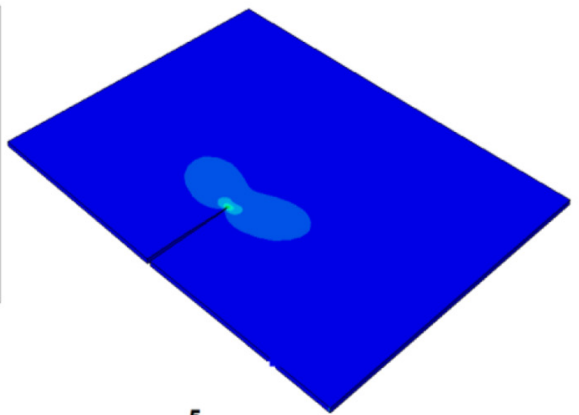

(c) $\mathrm{N}=3.8 \times 10^{5}$ cycles
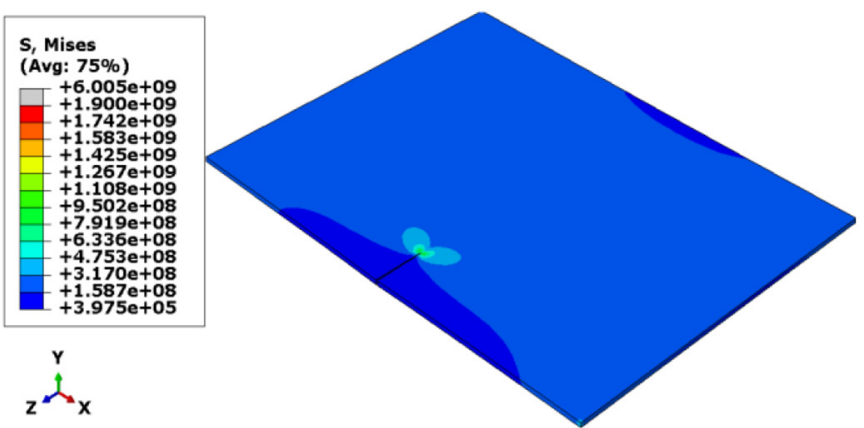

(b) $\mathrm{N}=3.4 \times 10^{5}$ cycles

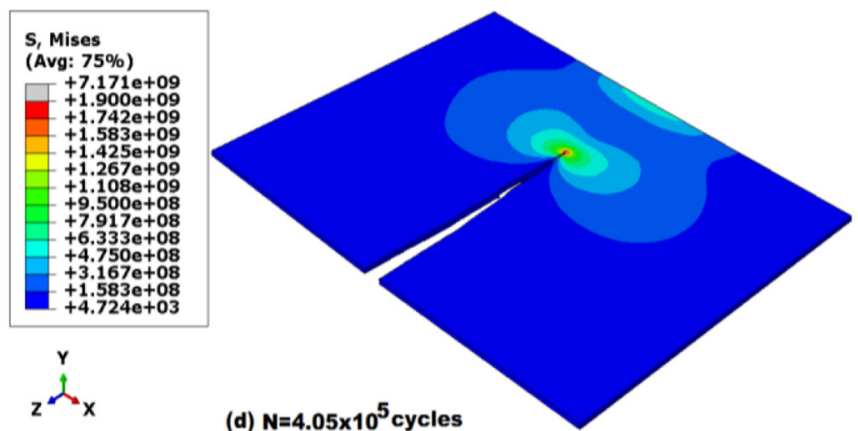

(d) $\mathrm{N}=4.05 \times 10^{5}$ cycles

Fig. 5. The effect of applied load only (without welding) on the crack opening and von Mises stress distribution for different crack lengths. 

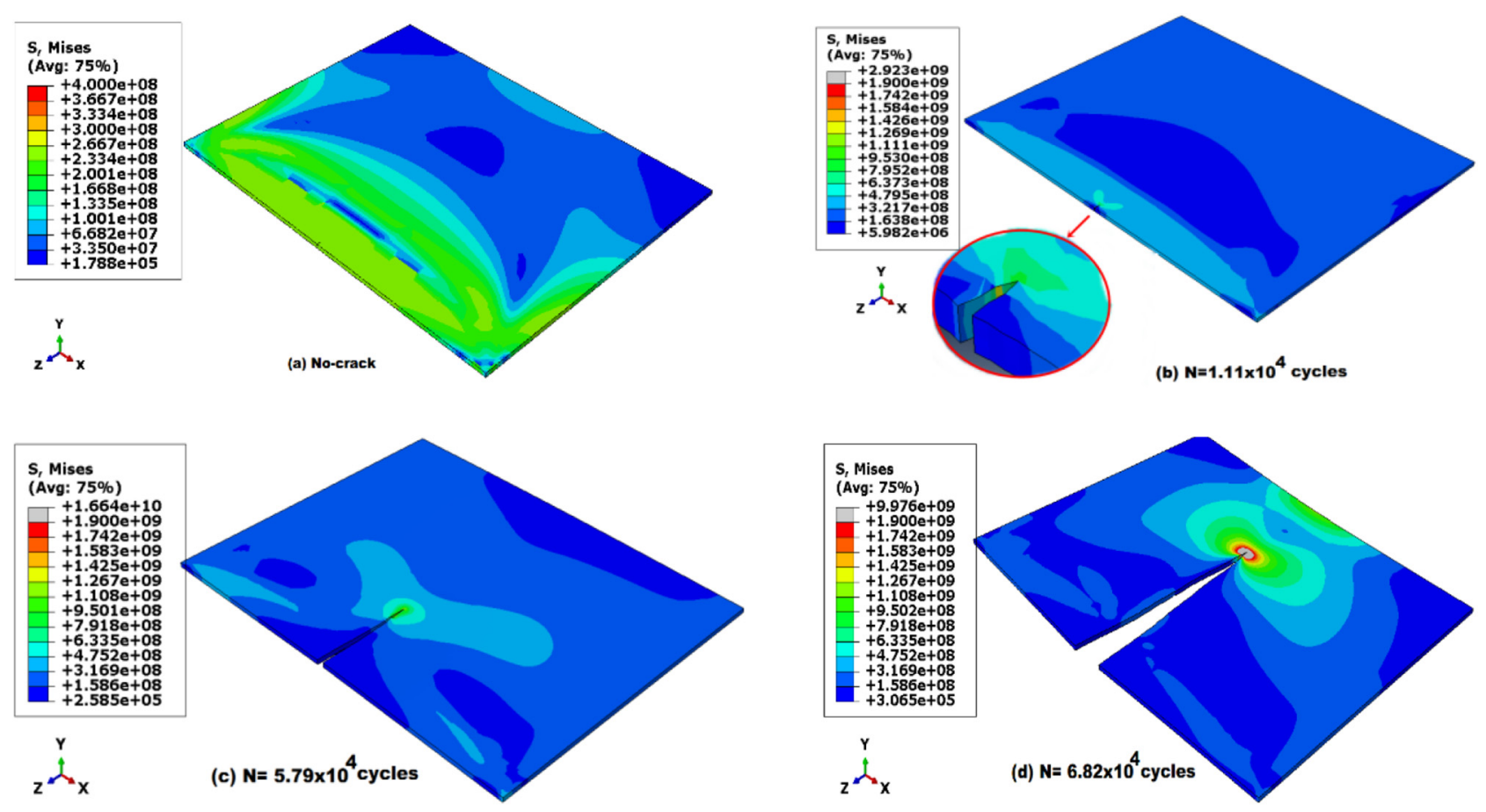

Fig. 6. The effect of residual stress and applied load on the crack opening and von Mises stress distribution at various crack lengths.

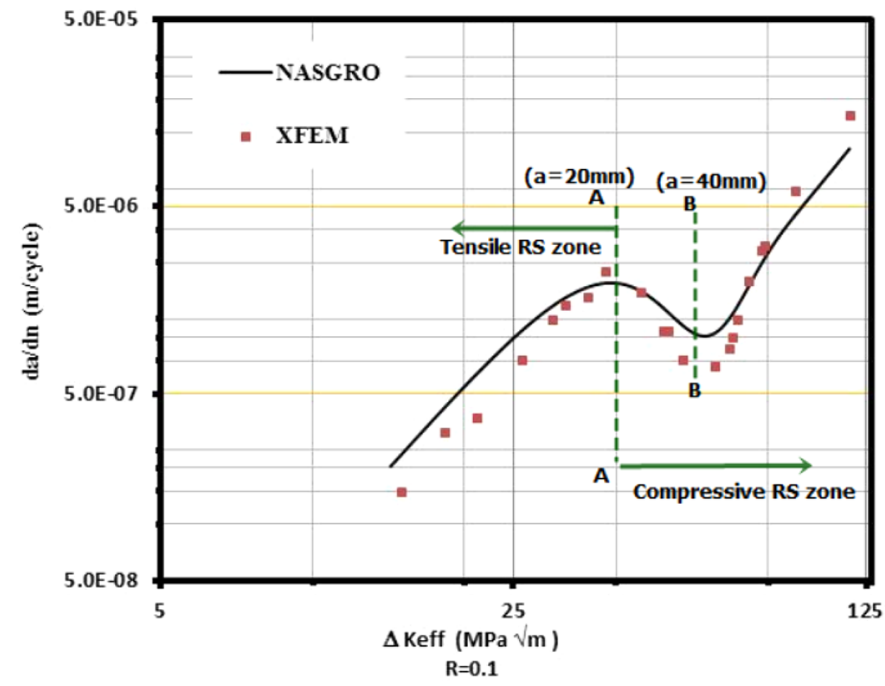

Fig. 7. The relationship between fatigue crack growth and effective stress intensity factor range through residual stress field.

welding residual stress. According to Figure 3, it can be noticed that the tensile residual stress zone would end, approximately, at a crack length a $20 \mathrm{~mm}$ i.e at section $\mathrm{A}-\mathrm{A}$ in Figure 7 . So, a faster crack growth rate is obtained when the crack is inside the tensile residual stress zone due to the effect of high tensile $K_{\text {res }}$ and $R_{\text {eff. }}$ Then, the crack growth rate slows down propagates under the effect of high compressive residual stress zone till $a=40 \mathrm{~mm}$ (section B-B). Following section B-B, Figure 7, the values of compressive residual stress raises again to balance tensile residaul stress and the $R_{\text {eff }}$ has insiginificant effect. Then, the crack growing continuous without the effect of residual stress as defined in Figure 4.

Moreover, the XFEM residual stress field indicates less correlation with the NASGRO model; this could be related to the assumption of dissimilar boundary conditions between the XFEM model and the mechanical model, which results in tiny variations in the stress field.

\section{Conclusions}

Welding simulations and fatigue crack growth rates through butt welded joints of 304 stainless-steel plates were investigated using ABAQUS 3D XFEM to consider the effects of residual stress. The results were verified using experimental data and the NASGRO model. Based on the results obtained, we conclude that:

- The XFEM can be successfully used to simulate fatigue crack growth in 3D geometry. The XFEM model without residual stress effects correlates well with experimental data and the NASGRO model, while the XFEM in the residual stress field displays less agreement with the NASGRO model. Therefore, the NASGRO model gives a better prediction of fatigue crack growth in the residual stress field than the XFEM model.

- Under cyclic loading, the residual stress field, especially the tensile one, reduces the fatigue life.

- The nature of residual stresses shows the detrimental effect of tensile stress and the beneficial effect of compressive stress on fatigue crack growth. Where a faster crack growth rate was found in the tensile stress zone, it then decreased gradually when moving to the compressive residual stress zone. 
- It is challenging to simulate crack propagation for a complicated structure, particularly in the presence of residual stress.

\section{Author Contributions}

Formal analysis: E. El Shrief and A. El Domiaty; Investigation: E. El Shrief and H. Abd El-Hafez; Methodology: E. El Shrief and A. El Domiaty; Software: E. El Shrief; Supervision: A. El-Megharbel.; Writing-Original Draft: E. El Shrief and H. Abd El-Hafez.; Writing-Review and Editing: H. Abd El-Hafez.

\section{Funding}

This is self-supported research without funding from any agency whatsoever.

\section{Conflicts of Interest}

The authors declare that there is no conflict of interest regarding the publication of this paper.

\section{References}

1. Y.E. Ma, P. Irving, Residual stress effects and fatigue behavior of friction-stir-welded 2198-T8 Al-Li alloy joints, J. Aircraft 48 (2011) 1238-1244

2. A.R. Shahani, I. Shakeri, Experimental evaluation of fatigue behaviour of thin Al5456 welded joints, Fatigue Fracture Eng. Mater. Struct. 43 (2020) 965-977

3. Y.W. Shi, B.Y. Chen, J.X. Zhang, Effects of welding residual stresses on fatigue crack growth behaviour in butt welds of a pipeline steel, Eng. Fract. Mech. 36 (1990) 893-902

4. Y.B. Lee, C.S. Chung, Y.K. Park, H.K. Kim, Effects of redistributing residual stress on the fatigue behavior of SS330 weldment, Int. J. Fatigue 20 (1998) 565-573

5. M.A. Sutton, A.P. Reynolds, Y.Z. Ge, X. Deng, Limited weld residual stress measurements in fatigue crack propagation: Part II. FEM-based fatigue crack propagation with complete residual stress fields, Fatigue Fracture Eng. Mater. Struct. 29 (2006) 537-545

6. C.D. Liljedahl, O. Zanellato, M.E. Fitzpatrick, J. Lin, L. Edwards, The effect of weld residual stresses and their re-distribution with crack growth during fatigue under constant amplitude loading, Int. J. Fatigue 32 (2010) 735-743
7. L. Zhu, M.P. Jia, A new approach for the influence of residual stress on fatigue crack propagation, Res. Phys. 7 (2017) 2204-2212

8. P. Ferro, F. Berto, M.N. James, Asymptotic residual stresses in butt-welded joints under fatigue loading, Theor. Appl. Fracture Mech. 83 (2016) 114-124

9. A. Bergara, J.I. Dorado, A. Martin-Meizoso, J.M. MartínezEsnaola, Fatigue crack propagation in complex stress fields: experiments and numerical simulations using the Extended Finite Element Method (XFEM), Int. J. Fatigue 103 (2017) $112-121$

10. E.A. Elshrief, A. El-Megharbel, A. Eldomiaty, H. Abdelhafez, Effect of crack orientation and residual stress on stress intensity factors of Butt-Welded steel joints, Port-Said Eng. Res. J. (in press), 2021. doi:10.21608/PSERJ.2021.44187.1065

11. R. Mishra, R.G. Burela, Thermo-electro-mechanical fatigue crack growth simulation in piezoelectric solids using XFEM approach, Theor. Appl. Fracture Mech. 104 (2019) 102388

12. N.A. Abdullah, M. Akbar, N. Wirawan, J.L. Curiel-Sosa, Structural integrity assessment on cracked composites interaction with aeroelastic constraint by means of XFEM, Compos. Struct. 229 (2019) 111414

13. M. Hashemzadeh, B.Q. Chen, C. Guedes Soares, Comparison between different heat sources types in thin-plate welding simulation, Developments in maritime transportation and exploitation of sea resources. Taylor \& Francis, 2014, 329-335

14. X. Hu, J. Xu, X. Du, Y. Zhang, F. Zhou, Research on Fatigue Crack Propagation of 304 Austenitic Stainless Steel Based on XFEM and CZM, Metals 10 (2020) 727

15. C.-H. Lee, K.-H.J.E.F.M. Chang, Finite element computation of fatigue growth rates for mode I cracks subjected to welding residual stresses, Eng. Fracture Mech. 78 (2011) $2505-2520$

16. L.W. Tsay, Y.C. Liu, M.C. Young, D.Y. Lin, Fatigue crack growth of AISI 304 stainless steel welds in air and hydrogen, Mater. Sci. Eng. A 374 (2004) 204-210

17. M. Benachour, N.J.I.J.o.M.M.E. Benachour, Effect of mean stress on fatigue crack growth behavior of stainless steel 304L, Int. J. Mech. Mechatron. Eng. 5 (2011) 2268-2271

18. S. Abdullah, S. Beden, A.J.A.A. Ariffin, Theory Applications, Fatigue crack growth simulation of aluminium alloy under cyclic sequence effects, Mater. Des. 31 (2011) 237-258

19. J.A. Correia, A.M. De Jesus, P.M. Moreira, P.J. Tavares, Crack closure effects on fatigue crack propagation rates: application of a proposed theoretical model, Adv. Mater. Sci. Eng. 2016 (2016)

20. Y. Luo, W. Gu, W. Peng, Q. Jin, Q. Qin, C. Yi, A study on microstructure, residual stresses and stress corrosion cracking of repair welding on 304 stainless steel: part i-effects of heat input, Materials 13 (2020) 2416

Cite this article as: Eman El Shrief, Abla El-Megharbel, Aly El Domiaty, Hassan Abd El-Hafez, Residual stress effects on fatigue crack propagation in Butt-Welded joints for 304 stainless steel sheets, Manufacturing Rev. 8, 19 (2021) 